\title{
Overview of Key Quality Characteristics Identification of Complex Electromechanical Products
}

\author{
Ma Li-sha ${ }^{1}$, Mao Jian ${ }^{1}$, Wan Zi-ping ${ }^{2}$ \\ (1.School of Mechanical Engineering, Shanghai University of Engineering Science, China; 2.School of \\ mechanical engineering and automation, National Defense Science and Technology University, China)
}

\begin{abstract}
Key quality characteristics identification of complex electromechanical products can be abstracted as the problem of dimensionality reduction of high-dimensional data in the model. Its purpose is to reduce irrelevant and redundant quality characteristics under the condition of information without loss as far as possible. The definition and classification of quality characteristics are introduced in the paper based on the research on quality characteristics. The principle and method of key quality characteristics identification are analyzed and described, and the current researches at home and abroad are summarized. At last, a summary and outlook. are given..
\end{abstract}

Keyword: Complex electromechanical products, quality characteristics, key quality characteristics

\section{Introduction}

Since the reform and opening up, the development of manufacturing has been rapidly, but there are still serious technical shortcomings in manufacturing industry. For example, the aviation engine manufacturing technology of complex equipment production has a great gasp compared with developed countries ${ }^{[1]}$. The production control of the equipment manufacturing industry is the key and difficult point in the manufacturing industry, and its development level represents the advanced level of the productivity of the manufacturing industry as a whole ${ }^{[2]}$. As more and more attention is paid to the complex equipment manufacturing industry, the research on the identification of the key quality characteristics of complex electromechanical products has been paid more and more attention. Compared with the key quality characteristics identification of traditional products, it is more difficult to identify the key quality characteristics of complex electromechanical products. Because the quality characteristics data set of complex electromechanical products has high dimension, including both the quality characteristics of the assembly process and the quality characteristics of the product parts $^{[3]}$. Identify the key quality characteristics of complex electromechanical products in the manufacturing process is an important part of product quality control. Choosing product parts quality characteristics from product design and manufacturing process and identifying key quality characteristics which have an important impact on product belong to feature selection in high dimensional space search. The research on them is conducive to further improve the theory of quality control and improve product quality control level ${ }^{[4]}$.

\subsection{Complex electromechanical products}

\section{Key Quality Characteristics of Complex Electromechanical Products}

Complex electromechanical products is a subsystem of complex product systems or components which has complex structure and manufacturing technology, the design process involves many departments compared with ordinary electromechanical products ${ }^{[5]}$. Complex electromechanical product is a complex system of machinery, electronics and control, according to need can also include hydraulic, pneumatic, software. The description of complex electromechanical products according to different scholars just as shown in Table 1. The quality problem of complex electromechanical products has received great attention in both academia and industry. There are a large number of complex electromechanical products in many industries, such as automobiles, railway vehicles, aerospace vehicles, robots etc..

Table 1. Feature description of complex electromechanical products

\begin{tabular}{|c|c|c|}
\hline Researchers & Feature description & year \\
\hline Zhang Gen-bao et al ${ }^{[6]}$ & $\begin{array}{l}\text { Machine, electricity, liquid, control, light, magnetic, thermal } \\
\text { and other physical processes were fused }\end{array}$ & 2010 \\
\hline Yin Chao et al ${ }^{[7]}$ & $\begin{array}{l}\text { High manufacturing costs, long assembly cycle, high quality } \\
\text { requirements }\end{array}$ & 2014 \\
\hline Chen Jin et al ${ }^{[8]}$ & $\begin{array}{l}\text { With a systematic and complex functions and interfaces, and } \\
\text { multi embedded software interface }\end{array}$ & 2005 \\
\hline $\begin{array}{l}\text { NAZARIAN } \\
\text { et al }^{[9]}\end{array}$ & $\begin{array}{l}\text { Contains a large number of parts, design professional } \\
\text { knowledge great span }\end{array}$ & 2013 \\
\hline Ceng Haifeng et al ${ }^{[10]}$ & It consists of many modules, such as mechanical, electrical, & 2010 \\
\hline
\end{tabular}




\subsection{Product quality characteristics}

As a measure of product quality, quality characteristics are the inherent attributes of products which are composed of various parameters that affect and determine the quality level. In order to realize the quality control of the product effectively, it is necessary to accurately describe and define the product quality characteristics. In general, the nature of the quality parameters can be divided into two forms: the true quality characteristics and the alternative quality characteristics ${ }^{[11]}$. The true quality characteristics are directly related to the quality of the customer's needs, which are often easier to identify. Alternative quality characteristics are the characteristics of the need for auxiliary control in order to meet the real characteristics of the product. According to different classification methods, the quality characteristics can be classified as shown in the following table ${ }^{[12]}$ :

Table 2. Quality classification

\begin{tabular}{|c|l|}
\hline Classification methods & \multicolumn{1}{c|}{ Classification results } \\
\hline Classification by quality dimension & $\begin{array}{l}\text { Function, performance, reliability, compliance, durability, serviceability, } \\
\text { appearance, perceived quality, etc. }\end{array}$ \\
\hline Classification by parameter type & $\begin{array}{l}\text { Quantitative characteristics (geometric size, chemical composition, physical } \\
\text { properties, chemical properties, etc.), qualitative characteristics (appearance and } \\
\text { operation requirements, etc.) }\end{array}$ \\
\hline Classification by attributes & $\begin{array}{l}\text { Geometric characteristics, mechanical properties, physical properties, chemical } \\
\text { properties, etc. }\end{array}$ \\
\hline Classification by type & Product level, component level, part level, characteristic level, process level, etc. \\
\hline Classification by forming process & $\begin{array}{l}\text { Design quality characteristics, manufacturing quality characteristics, assembly } \\
\text { quality characteristics, the use of quality characteristics, etc. }\end{array}$ \\
\hline Classification by importance & $\begin{array}{l}\text { Key quality characteristics, important quality characteristics, general quality } \\
\text { characteristics }\end{array}$ \\
\hline
\end{tabular}

The most important principle of the classification of quality characteristics is to grasp the key minority in many quality characteristics. According to the importance of the quality characteristics, the quality characteristics can be divided into the key quality characteristics, the important quality characteristics and the general quality characteristics. Importance classification should reflect the severity of product failure and not be used as a means of generating additional requirements. The classification limits, treatment methods and marks of the quality characteristics are shown in table ${ }^{[13]}$ :

Table 3. Classification method of quality characteristic importance

\begin{tabular}{|c|l|l|c|}
\hline Feature level & \multicolumn{1}{|c|}{ Classification limit } & \multicolumn{1}{|c|}{ Processing method } & Sign \\
\hline Critical level & $\begin{array}{l}\text { The error will lead to serious deviation, the main function } \\
\text { of the product will immediately lose after the failure, } \\
\text { resulting in the emergence of substandard products, } \\
\text { causing significant economic losses to businesses and } \\
\text { consumers. }\end{array}$ & No one has the right to move on & [A] \\
\hline Important level & $\begin{array}{l}\text { The error within the allowable range will have a certain } \\
\text { impact on the quality of the final product, partial function } \\
\text { of products will lose after failure. }\end{array}$ & $\begin{array}{l}\text { Be reused after the approve of } \\
\text { design and process department, } \\
\text { be stored after quality inspection }\end{array}$ & [B] \\
\hline General level & $\begin{array}{l}\text { The error within the allowable range has little effect on the } \\
\text { final quality of the product, the economic loss will be } \\
\text { smaller after failure }\end{array}$ & $\begin{array}{l}\text { Handles by the quality inspection } \\
\text { department }\end{array}$ & [C] \\
\hline
\end{tabular}

\subsection{Product key quality characteristics}

There are three principles to define key quality characteristics: Firstly, affecting the loss of safety and function. Secondly, affecting characteristics of product life, performance and adaptability. Thirdly, searching for historical data from waste products, defects, and nonconforming products ${ }^{[14]}$. The concept of the key quality characteristics originates from the customer's demand, and it is continuously replenished and expanded in the subsequent production and development of the enterprise. The experts and scholars have their own definition of the key quality characteristics, such as Chinese scholars He Yihai, Tang Xiaoqing defined as the basic unit of information to determine and control the quality of products". Some foreign scholars have also defined it, although describe from different angles, but the basic thought is similar ${ }^{[15]}$. It is worth mentioning that the General Motors (GM) pointed out that to determine key quality characteristics according to the close relationship between the process and the manufacturing capability of a quality characteristic and the cost of the enterprise $^{[[6]}$. 


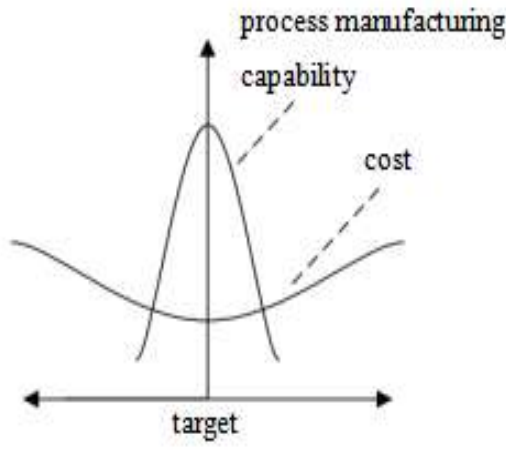

Fig1. Non KQCs

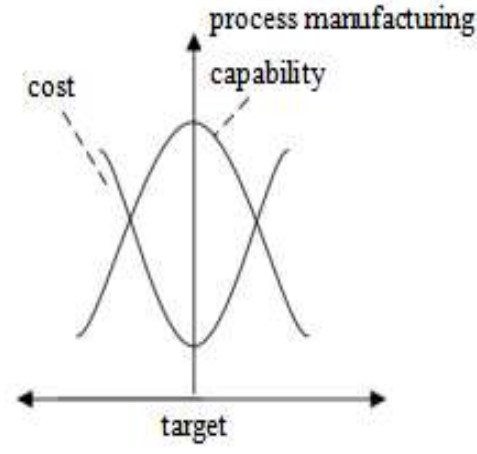

Fig2. KQCs

Figure 1 shows that a change in the manufacturing process of a quality characteristic process does not cause a drastic change in cost, so it is considered to be a key quality characteristic of the non product, which is obviously of little practical significance. Figure 2 shows that a change in the manufacturing capacity of a particular process can seriously affect the cost of change, so it is considered to be the key quality characteristic, which should be kept in the most effective range. However, in the cost curve of this control method, the relationship between the change of product characteristics and product cost is influenced by subjective factors.

\section{Identification of Key Quality Characteristics}

\subsection{The principle of identifying key quality characteristics}

The structure of complex electromechanical product is complex, and the original expansion method can not solve the problem of design tolerance in the production process. Furthermore, it is difficult to define the relationship among the quality characteristics when it is expanded to the component level. The principle of identifying the key quality characteristics of complex electromechanical products is that the quality characteristics are analyzed and screened, and the quality characteristics which have no significant influence on the quality of the products are filtered through the classifier and the criterion in the production process ${ }^{[17]}$.

\subsection{Methods to identify key quality characteristics \\ 3.2.1 Quality Function Deployment (QFD)}

Quality function deployment is a kind of systematic and user driven approach for quality assurance which is committed to maximize meet customer needs in the process of product development. The basic principle is to find out the key measures in the form of "house of quality" ${ }^{[18]}$. QFD is a quantitative identification method used in the product design stage. It is based on customer demand, and the key quality characteristics are decomposed into parts and process characteristics. However, with the increase of the complexity of the product, the construction of the relational matrix becomes more and more difficult.

\subsubsection{Principal Component Analysis (PCA)}

Principal component analysis was firstly pointed out by Hotelling. It combines the original information into a set of mutually independent few independent comprehensive indexes and use it to replace the original index ${ }^{[19]}$. The new index can reflect the main information of the original index. The method uses the idea of dimension reduction, finds the principal component variables by linear transformation. It is suitable for all stages of product life cycle with less design, lower cost. But it still needs to measure all the characteristics, and can not really reduce the nature of the actual.

\subsubsection{Date Mining (DM)}

Data mining is a process of extract implicit useful information from a lot of incomplete, noisy, fuzzy, random practical application data $\left.{ }^{[20}\right]$. The data mining process includes the preliminary analysis and definition, data preprocessing, the using process of data mining method, the results of mining information obtained by analyzing and sorting, the use of information and other parts, just specific as follows ${ }^{[21]}$ :

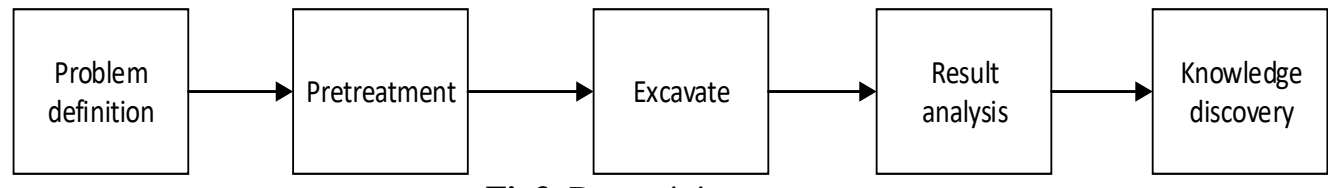

Fig3. Data mining process 
The main tasks of data mining include association analysis, classification analysis and prediction analysis $^{[22]}$. Association analysis was first proposed by Rakesh Apwal, the most classic algorithm is Apriori algorithm. Classification analysis refers to the process of classifying a given sample data into a certain category by a classification model. Predictive analysis is to find out the rules of some data from time to time, and to predict the unknown information.

\subsubsection{Feature clustering}

Feature clustering is the process of automatically dividing the clustering objects into several groups according to a certain rule. The traditional clustering method can be divided into the hierarchical method and the partition method. The $\mathrm{K}$ method and the improved algorithm are better than the well-known methods. With the continuous development of the algorithm and the emergence of the density method (such as DBSCAN), based on the network method and model based method. The five methods are called modern classical clustering methods. Now, there are some clustering methods, such as SOFM, Bi dimensional clustering and so on.

\subsubsection{Feature selection \\ (1)Filter method}

The filter method determines the feature subset through certain metrics and evaluates subset according to certain evaluation standard, and then test evaluation index whether meet the stop condition. If satisfied, it will jump out of the subset search, otherwise continue to search and evaluate the next subset. The specific implementation steps of multivariate Filter are as follows ${ }^{[23]}$ :

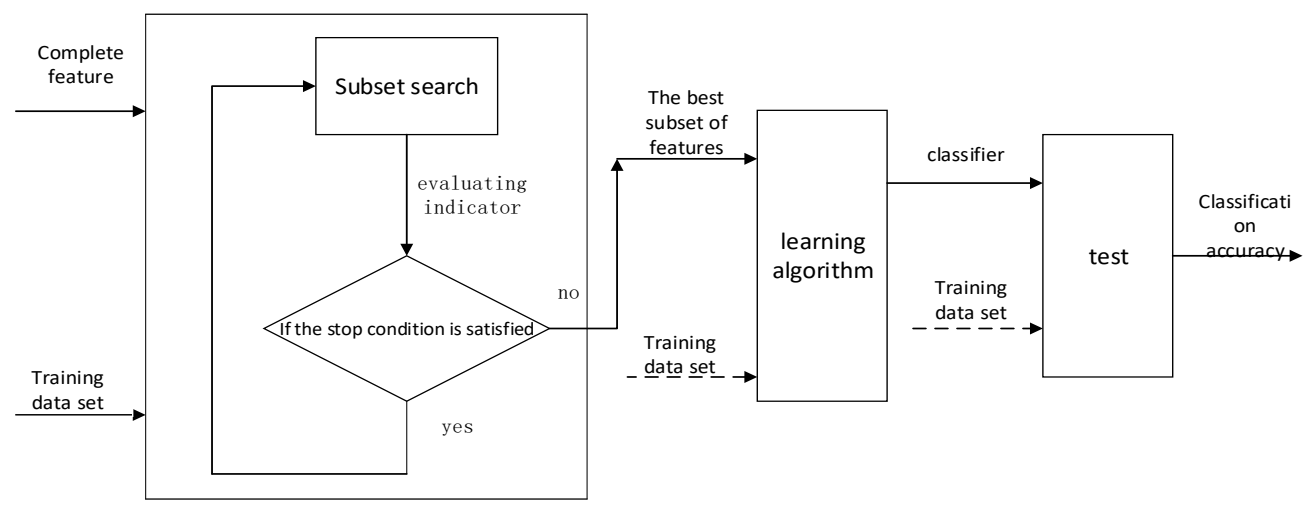

\section{(2)Wrapper method}

Fig4. The steps of Filter method

The Wrapper method is a very direct method for selecting feature subsets. Different from Filter, the wrapper method is combined with specific classifiers and embeds the hypothesis space of the model into the search of the feature subset. To evaluate the accuracy of classification through cross validation, and to select a group of feature subset of the highest classification accuracy as the feature subset. The concrete implementation steps of the Wrapper method are as follows ${ }^{[23]}$ :

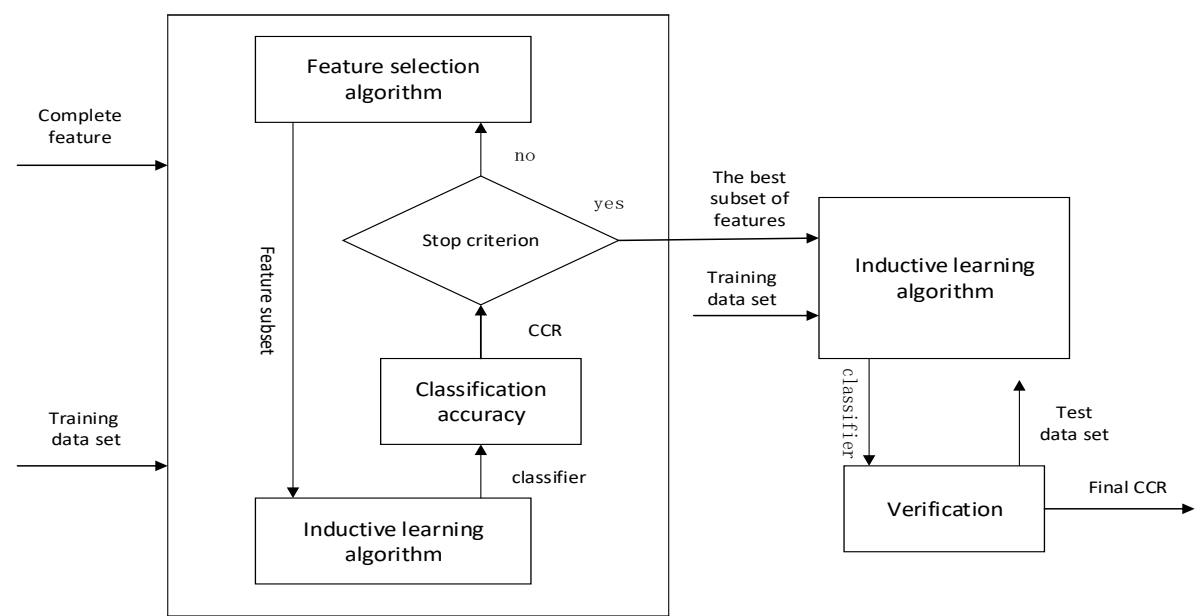

Fig5. The steps of Wrapper method 


\section{(3)Embedded method}

Embedded method is a kind of method which combines the Filter method with Wrapper to make its advantages complementary. In this method, the feature selection is realized by embedding the basic algorithm in the classification algorithm, the concrete implementation steps of the Embedded method are as follows ${ }^{[24]}$ :

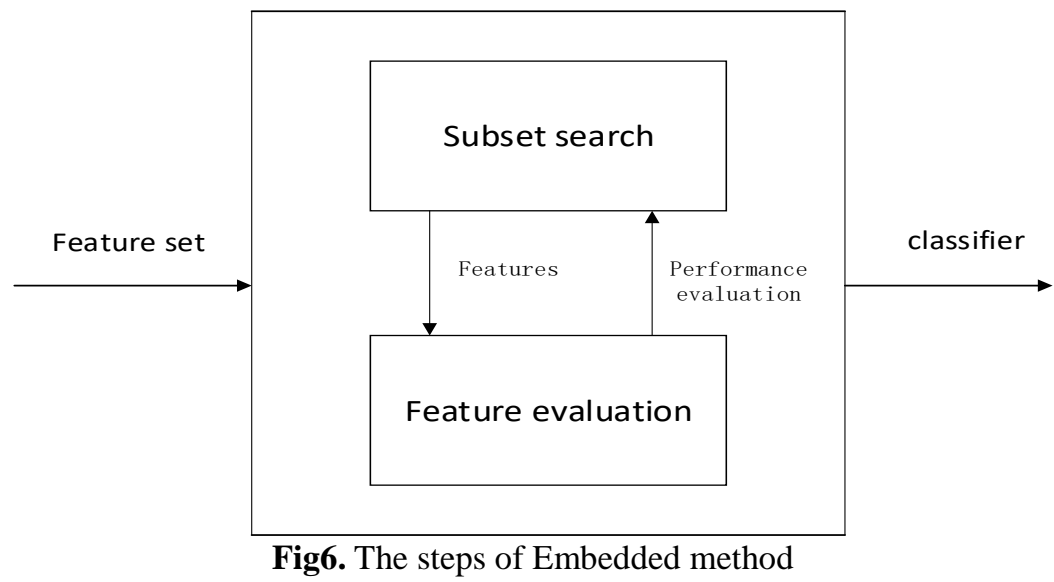

\section{Related Research At Home And Abroad}

The home and abroad has experienced from qualitative to quantitative, from the design level to the production level, from the low dimensional data to the processing process of high-dimensional data about the study of key quality characteristics for the product identification issue.

\subsection{Product design phase}

In the product design stage, the researchers mainly use the quality function deployment (QFD) method to identify KQCs, the key step is to establish the relationship matrix. The main application of QFD is to deal with the problems of low dimension and small system, but the complex product has the characteristics of high dimension, multi level and fuzzy user needs. So, the identification relies on the four phase expansion model. Huang Tiequn et al. ${ }^{[25]}$ introduced the quality characteristics model of the process. Due to the complexity of the product and the difference between the design process and the actual production quality inspection process, only from the design level of KQCs identification can not meet the requirements.

\subsection{Product manufacturing stage}

Research on manufacturing process KQCs recognition, the domestic representative research in recent years are: He Yihai et al. ${ }^{[26]}$ proposed a reliability modeling and analysis method for manufacturing system based on process quality data; Zhang Genbao et al. ${ }^{[27]}$ put forward the KQCs model and the KQCs optimization model of complex electromechanical products based on artificial neural network (ANNs) technology; Shen et al. ${ }^{[28]}$ proposed a quality factor screening method for discrete event simulation experiments based on sequential factor test. The recognition of KQCs in manufacturing process can be attributed to the dimensionality reduction of high-dimensional data. The two basic methods are feature selection and feature extraction. According to the two methods, Yan Wei ${ }^{[29]}$ using Filter algorithm for KQCs identification. Xie Rongqi et al. ${ }^{[30]}$ introduced the characteristics in the area of data mining clustering method aiming at the defects of Filter method, and got some KQCs subsets with strong correlation and less mad. He Zhen et al. ${ }^{[31]}$ introduced the Cost-sensitive model into the information gain, and proposed a new method of KQCs based on the improved IG algorithm for the high dimensional imbalanced data sets. Song Libin et al. ${ }^{[32]}$ applies Mahalanobis Taguchi method to product KQCs identification, and proves the validity of this method in KQCs recognition by an example.

\section{Conclusion And Prospect}

The paper simply analyzes the definition of complex electromechanical products, the classification of quality characteristics, the principles and methods of the key quality characteristics identification of complex electromechanical products. It aims to contribute to the follow-up research work. It is difficult to solve the problems of control and diagnosis in the manufacturing process. This poses many challenges to the existing process control methods. As the foundation of the quality control and diagnosis of complex electromechanical products, the identification of key quality characteristics has become a frontier issue. The key quality characteristics of the product category are determined by the critical quality characteristics of the parts. So, it is necessary to study and identify the key quality characteristics of parts in order to control the key quality 
characteristics of product level. In the complex electromechanical product quality control process, how to establish the quality control model accurately has become a problem of complex electromechanical product key quality characteristics recognition. The identification can be summarized as seizing the "key minority" for further control among the many quality characteristics so as to achieve the purpose of improving the quality of products and reducing the detection cost in the production process of complex electromechanical products.

\section{Reference}

[1]. Li B H. The important technology of complex product manufacturing information system integrated manufacturing system of complex products. China Manufacturing Information, 2006, (14): 18-23.

[2]. Bai Y X, Zhao Y. Development trend and Countermeasures of China's equipment manufacturing industry in post crisis era Fujian Forum (HUMANITIES AND SOCIAL SCIENCES EDITION), 2010, (7): 4-8.

[3]. Wei S, Ruxin N, Jianhua L, et al. Assembly process simulation for flexible cable harness in complex electromechanical products. Journal of Computer-Aided Design \& Computer Graphics, 2012, 6: 016.

[4]. Tang W B, Yu J F, et al. Study on the application of quantitative identification and decomposition method of the key characteristics of the product. Integrated Manufacturing System, 2011, 17 (11).

[5]. Pang J H. Research on some key technologies of design quality of complex electromechanical products. Chongqing University, 2011.

[6]. Zhang G B, Zeng H F, Wang G Q, et al. Decoupling model of quality characteristics for complicated electromechanical products. Chongqing Daxue Xuebao(Ziran Kexue Ban), 2010, 33(5): 7-15.

[7]. Yin C, Gan H, Liang Z Q et al. Evaluation and early warning method of material quality loss in key assembly process of complex electromechanical products. Computer Integrated Manufacturing System, 2014, 20 (6): 1432-1442.

[8]. Chen J, Zhou Z F, et al. Study on the process model of complex product system innovation. Scientific Research Management, 2005 , 26 (2): 61-67.

[9]. Ko J, Nazarian E, Wang H, et al. An assembly decomposition model for subassembly planning considering imperfect inspection to reduce assembly defect rates. Journal of Manufacturing Systems, 2013, 32(3): 412-416.

[10]. Zeng H F. Coupling analysis and decoupling control of quality characteristics of complex electromechanical products. Chongqing University, 2010.

[11]. Lin Z H. Product design and manufacturing quality engineering. Beijing: China Machine Press, 2005.

[12]. D. Wanga, Rajagopalan Srinivasan. Multi-model based real-time final product quality control strategy for batch processes. Computers and Chemical Engineering, 2009, 33: 992-1003.

[13]. Liu H. The important role of the classification of the importance of product quality characteristics in the quality chain. Electronic Quality, 2007, (1): 45-47.

[14]. Lu Z. Study on key quality characteristics and quality control technology of typical shaft parts. Zhejiang University, 2014.

[15]. He Y H, Tang Xiaoqing. Design of product quality based on key quality characteristics. Journal of Aeronautics, 2007, 28 (6): 1468-1481.

[16]. Yan W. Research on the method of identifying the key quality characteristics of complex products based on data mining. Tianjin University, 2012

[17]. Yan W, He P, Li A D et al. Identification of key quality characteristics of complex products based on CEM-IG algorithm. Systems Engineering Theory and Practice, 2014, 34 (5): 1230-1236.

[18]. Li Y L, Tang J F, et al. Multi objective decision making method for selecting engineering characteristics in quality function deployment. Computer Integrated Manufacturing Systems, 2008, 14 (7): 1363-1369.

[19]. Zhao J, Li L M. Principal component analysis and comprehensive evaluation of robot global performance method and kernel based on the principal component analysis. Journal of Beijing University of Technology, 2014 (12): 1763-1769.

[20]. Kantardzic M. Data mining: concepts, models, methods, and algorithms. John Wiley \& Sons, 2011.

[21]. Low Y, Bickson D, Gonzalez J, et al. Distributed GraphLab: A framework for machine learning and data Mining in the cloud. Proceedings of the VLDB Endowment, 2012, 5(8): 716-727.

[22]. Xie R Q. Research on data mining model for identification of key quality characteristics of complex products [D]. Tianjin University, 2013.

[23]. Li A D, He P, He S G et al. Identification of key quality characteristics of complex products based on the Filter and Wrapper. Industrial Engineering and Management, 2014, (4): 53-59.

[24]. Tian W M. Research on the method of product quality control based on feature selection. Tianjin University, 2013.

[25]. Huang T Q, Xu S L. Evaluation of the main template for process planning based on quality function deployment. Computer Integrated Manufacturing System, 2010, 16 (6): 1183-1188.

[26]. He Y H, Shen Z, et al. Reliability modeling of manufacturing system based on process quality data. Journal of Beihang University, 2014, 40 (8): 1027-1032.

[27]. Zhang G B, Ji F Y, Ren X L. Key quality characteristics of complex electromechanical product extraction model. Journal of Chongqing University (NATURAL SCIENCE EDITION), 2010, 32 (2): 8-14.

[28]. Shen H, Wan S, Controlled sequential factorial design for simulation factor screening, European Journal of Operational Research, 2008,09(05):100-105.

[29]. Yan W, He Z, TianW M et al. Identification of key quality characteristics of unbalanced data based on EM. Industrial Engineering and Management, 2012, 17 (4): 38-42.

[30]. Xie R Q, He Z, He S G. Identification of key quality characteristics of complex products based on the ReliefF and k - modes. Engineering Industry and Management, 2014, 19(1): 30-34.

[31]. He Z, Tian W M et al. Identification of key quality characteristics of complex products based on IG. Industrial Engineering and Management, 2012, 17 (1): 70-74,83.

[32]. Song L B. Research on the identification of the key quality characteristics of products based on Mahalanobis Taguchi method. Tianjin University, 2010. 